\title{
Neurocritical Care in Developing Countries
}

\author{
Farrah J. Mateen
}

Published online: 24 August 2011

(C) Springer Science+Business Media, LLC 2011

\begin{abstract}
Neurocritical illness heavily burdens the developing world. In spite of a lack of resources for population-based health in most developing countries, there is an increasing demand for resource-intense strategies for acute neurological care. Factors including rising individual incomes in emerging economies, need for neurointensive care in humanitarian emergencies, growth of private hospitals, the rising burden of noncommunicable disease, and the practice of neurocritical care by specialists outside of neurology are discussed. Possible steps to improve the global practice of neurocritical care include: (1) emphasis on prevention of neurocritical illness through traffic safety and adequate outpatient treatment; (2) standardization of training requirements and skill sets; (3) guidelines on costeffective measures including medications, equipment, and devices; (4) strengthening of surveillance systems and registries for both noncommunicable and communicable neurological diseases; (5) expanded use of teleneurology; (6) educational exchanges of neurointensive health care workers; and (7) monitoring of neurological intensive care unit death rates due to nosocomial infections, neurological disease, and other causes. A summary of reported mortality rates among neurocritically ill patients in African countries in recent years is provided as an illustrative example.
\end{abstract}

\section{F. J. Mateen $(\bowtie)$}

Department of Neurology, Johns Hopkins Hospital, The Johns Hopkins University, Pathology Building, Room 627, 600 North Wolfe Street, Baltimore, MD 21287, USA

e-mail: fmateen@jhsph.edu

\section{F. J. Mateen}

The Department of International Health, The Bloomberg School of Public Health, Johns Hopkins University, Baltimore, USA
Keywords Stroke $\cdot$ Trauma $\cdot$ Neurology $\cdot$ Intensive care · Neurologist $\cdot$ Developing countries

Neurocritical illness burdens the developing world, at times heavily and without the necessary resources, training, and facilities to provide the care that is very much needed. Infectious diseases are a major cause of neurocritical illness in developing countries, including meningitis, encephalitis, and cerebral malaria. Beyond infectious disease, there is now an even greater need to combat and address acute presentations of chronic disease. Ischemic and hemorrhagic stroke, severe head injury, and epilepsy are major unaddressed causes of morbidity and mortality in most developing countries. In addition to these highly prevalent disorders, neurological manifestations of rabies, tuberculosis, tetanus, organophosphate poisoning, and eclampsia remain smaller but important burdens of disease.

What then is the role of neurocritical care in the developing world? From one perspective, there is a lack of resources for population-based health in most developing countries. Yet, simultaneously, there is an increasing demand for resource-intense strategies for acute neurological care in these same settings. What can be learned from existent neurocritical care practices in developing countries to date? Why should neurocritical care be practiced worldwide?

First, rising incomes are experienced globally and asymmetrically, creating new upper and middle classes in some of the world's rapidly developing regions. For example, the absolute number of people considered "middle class" is greater in China than in the United States of America. This rising middle class has attributes and lifestyle-related habits that may put them at higher risk for neurocritical illness, including longer life span, 
hypertension, tobacco abuse, and increased transportation use. They may also be able to afford and access care that has not traditionally been prioritized in the health systems of some countries.

Second, a low gross national income at a country level does not equate to an absence of intensive care units (ICUs) (Fig. 1). Although ICUs are expensive and severely underresourced in many locations, they treat a high number of patients, particularly in urban centers. In some countries, including least developed countries, governments fund hospitals that necessarily include ICUs. Humanitarian assistance groups and military hospitals may also include some form of management of acute head injury, meningitis, and seizures, even in fragile states and least developed countries. This means that neurocritical care may still be practiced and life-saving in extremely resource-poor locations. Neurointensivists may serve some of the most vulnerable patient populations and in times of extreme need.

Third, other specialties are recognized as having an acute or intensive care component to them, including surgery and cardiology, while neurology is often ignored in this regard. This suggests that neurocritical care is practiced but may not be formalized into a subspecialty. Just as neurology in general is usually not practiced by neurologists (instead being practiced by psychiatrists, general practitioners, and internists), neurocritical care is often practiced by neurosurgeons, general surgeons, and cardiologists. Medical ICUs may be filled with neurological patients but the recognition that a neurologist should be consulted, trained, or helpful in such circumstances often needs concerted promotional efforts. Neurocritical care may even be common but is overlooked and not quantified.

In a trend that is likely growing, private hospitals exist as islands of high resource care in some of the poorest regions of the world. These hospitals may employ greater numbers of health care workers per patient than a typical ICU in a high income country. The wages provided by private hospitals can drain physicians from the public sector in that region, leading to a relatively high number of neurologists in private clinics and hospitals where neurocritical care may be more likely to be practiced. Hiring of neurologists into the private sector can develop neurocritical care practices in countries where more limited government investment would have not considered or prioritized this need.

The establishment of neurocritical care in the United States is rooted in the poliomyelitis outbreaks of the early twentieth century [1]. Although the iron lung was replaced by newer techniques for ventilatory support and polio outbreaks ceased, the role of the intensivist continued to evolve to responsibility for other neurological diseases and presentations. In the 21 st century, the development of

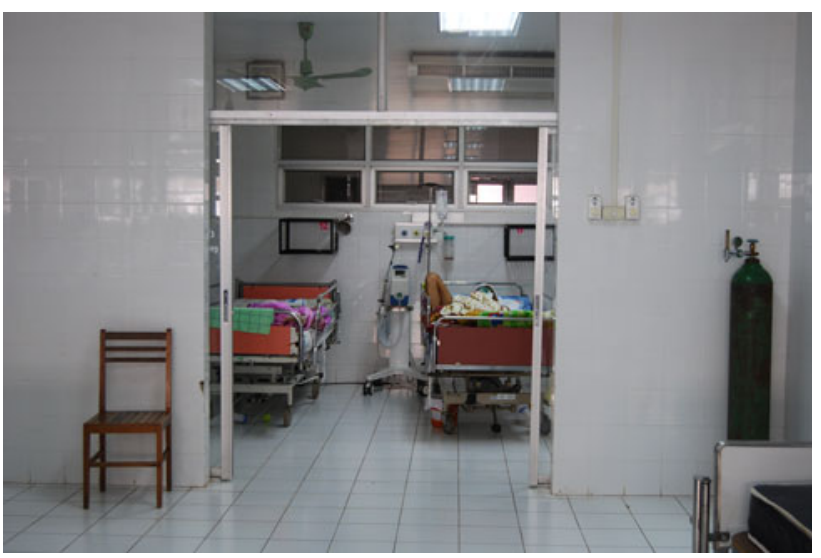

Fig. 1 A patient recovering from acute ischemic stroke in the intensive care unit of Mittaphab Hospital, Vientiane, Lao People's Democratic Republic

neurocritical care must be motivated by the growing burden of chronic noncommunicable diseases. Although not directly comparable, a summary of causes of acute care for neurological illness reported in medical journals from African countries in recent years (whether the patients were admitted to a formal ICU or not) demonstrates that mortality is high and much work is needed to improve the current situation, including in children [2-18] (Table 1). Whether these deaths are primarily due to the severity of neurological injury, late presentations to hospital, inadequate resources for intensive care needs, nosocomial infections, or other factors remains unclear. The mortality rates of patients in neurocritical settings deserve special attention. Existence of hospitals who accept acute neurological patients is insufficient. Significant coordination is required to finance, support, and sustain the work of practitioners of neurocritical care.

Solutions are possible and important. Neurocritical care everywhere can benefit from the growing organizational efforts of neurointensivists in high income countries who are standardizing skill sets and certification as well as fostering research opportunities. Private-public partnerships between health care facilities, local businesses, and drug and technology companies can also promote the way forwards. This includes commitment to drug delivery outside of urban settings and strengthening capacity for drug manufacturing in countries that can distribute within the developing world. Although tissue plasminogen activator is a standard of care for acute ischemic stroke in higher income settings, developing countries struggle with poor drug availability, poor medical facility organization, and poor community awareness of disease beyond the more clear indicators of absolute poverty. As such, snake venom, urokinase, and even unproven forms of acute stroke treatment may be employed when real treatments exist. 


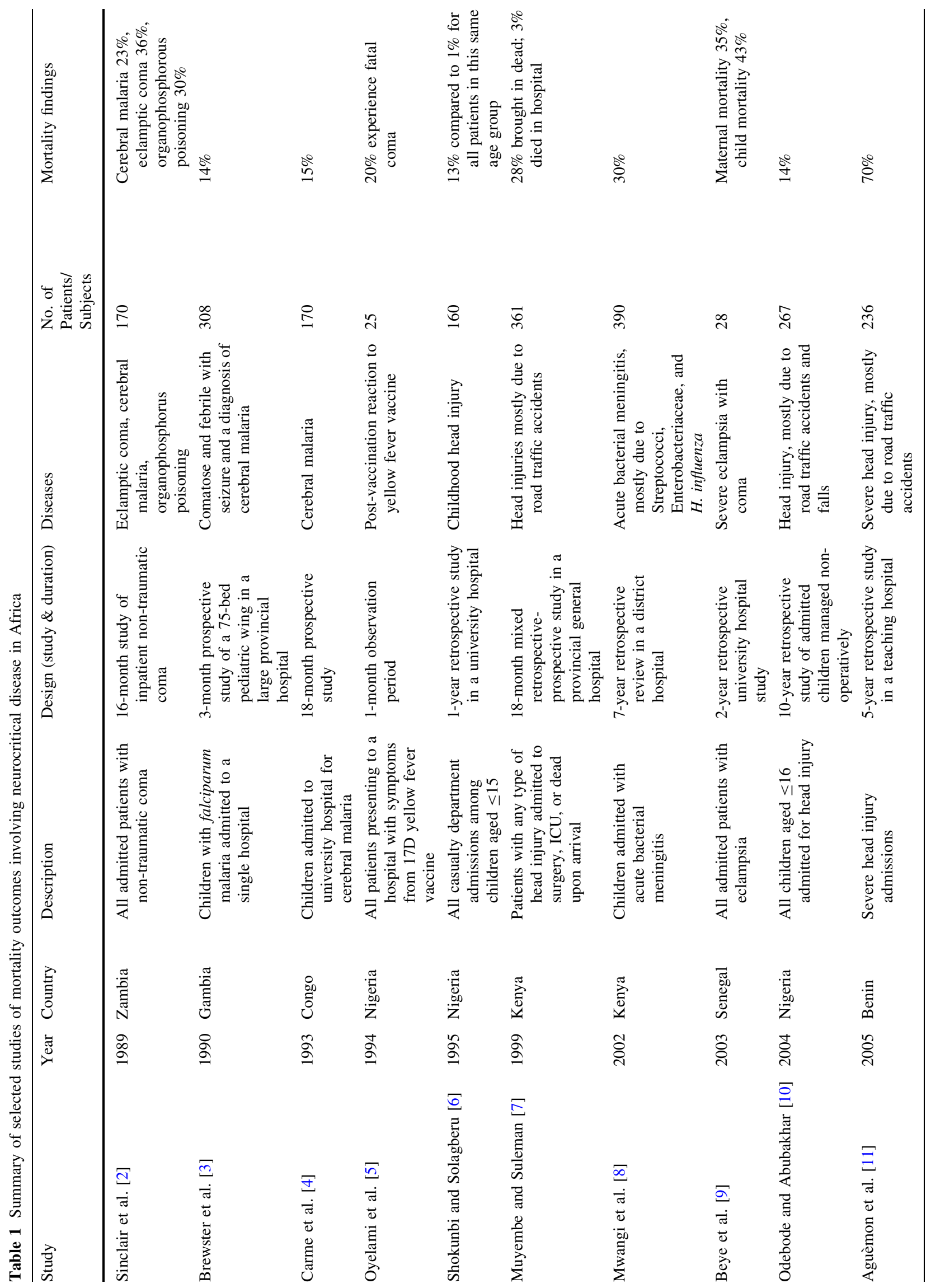




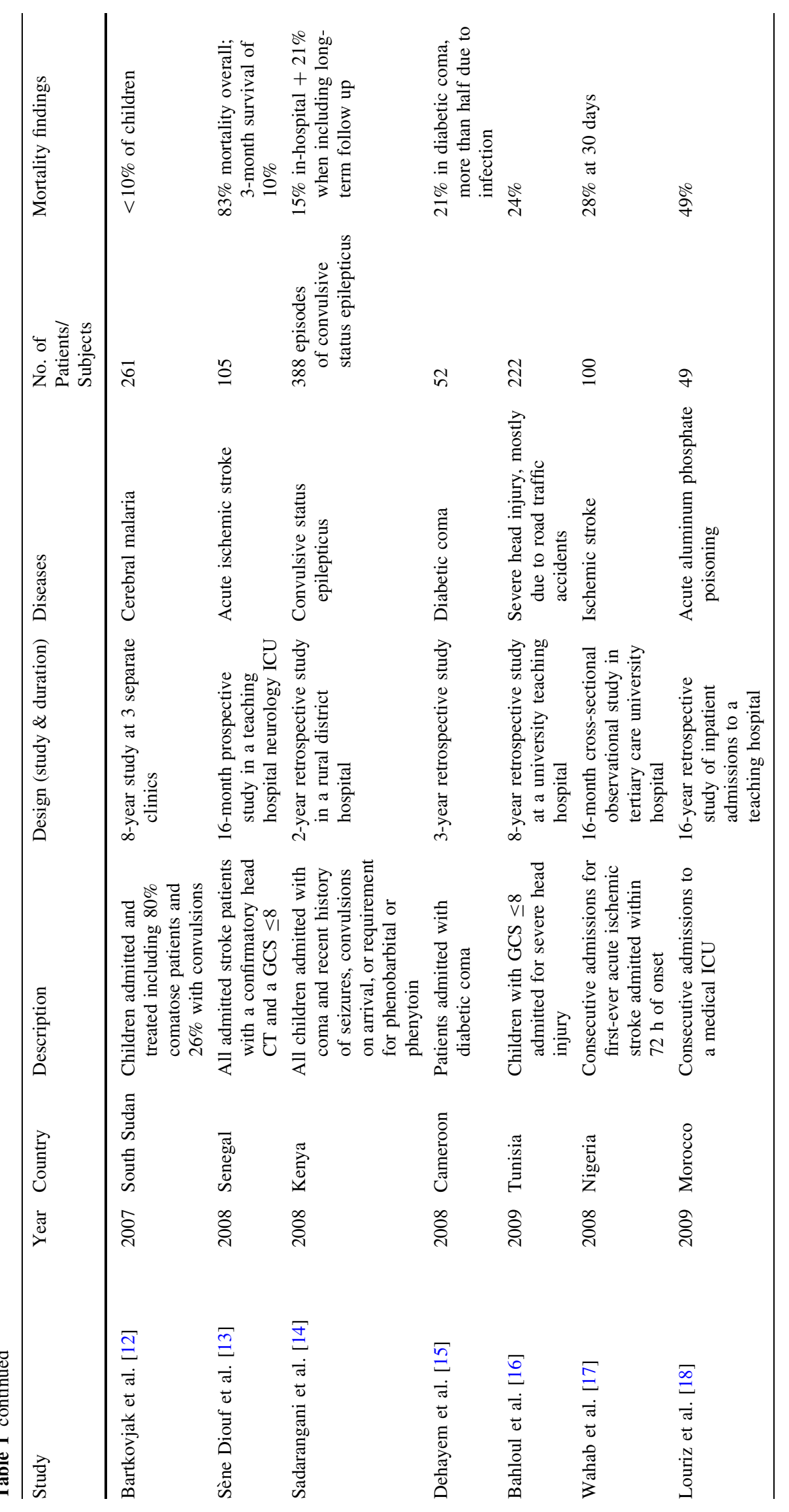


Similarly, magnesium for eclampsia is still not universally available, not because it is too expensive but because the demand for magnesium is unquantified and the profitability unclear to companies. More recently, the prospects of solar-powered blood pressure cuffs [19] and fluoxetine for motor recovery in stroke [20] have the potential for scaleup. These interventions may help meet the growing need to improve long term outcomes.

Convincing ethical arguments exist to bring neurocritical care to whole populations in developing countries and not just those who can pay. Many aspects of neurocritical care can be practiced in most developing countries in reliable, affordable, and pragmatic ways; however, care without attention to neurological recovery post-admission and standard hygiene practices is an ignoble goal. Where intensive care is practiced, in low income settings as well as wealthier ones, it must have a clear endpoint and realizable goal. Most importantly, responsible neurocritical care must be incorporated into the ideally seamless continuum between prevention, intervention, recovery, and rehabilitation. Although it may be simpler to say that there are no resources for neurological intensive care for the poorest poor, the human face of the growing burden of neurological injury worldwide obliges policy makers, medical practitioners, and ministries of health to find a more nuanced and workable approach. Developing countries deserve possibilities for neurocritical care that respond to the changing needs of populations in poverty.

What can be done to improve the situation for patients with neurocritical illness in resource-poor regions?

(1) Prevention: Helmets, seatbelts, speed bumps on roads, provision of aspirin, blood pressure monitoring, smoking cessation measures, epilepsy treatment. Primary care reduces the need for neurocritical care.

(2) Standardization of training requirements and skill sets for the practice of neurology and neurocritical care.

(3) Guidelines for the use of certain treatments, practices, and procedures in the care of neurocritical patients in all settings. This may include recommendations for such simple things as sequential compression devices or compression stockings, bedside swallowing tests, antibiotic prophylaxis, or daily aspirin use. Ideally, this should include the care of both children and adults. It may also identify a list of unproven, experimental, and unclear treatments for further study.

(4) Strengthening of surveillance systems and registries for chronic neurological disease and neurocritical illness. A knowledge of the burden of disease that exists will help set priorities for funding and raise the profile for neurocritical care on the international health agenda.
(5) Global neurocritical care educational exchanges which include training opportunities for physicians on both short and long term bases.

(6) Teleneurology: The potential to diagnose and exchange information in a timely way around the world is now realizable and potentially cost-effective, making use of limited expertise for different challenging situations.

(7) Monitoring of ICU death rates and nosocomial infections in neurocritical illness. An accurate assessment of the ability to prevent complications in neurocritical care patients is an important foundational step for evaluating the successes and failures of work to date. At best, a record of non-neurological threats to neurological patients in low resource settings can lead to simple and widespread measures to improve patient outcomes.

As in all places, the neurointensivist in the developing world faces challenges. These challenges are compelling and worthy of greater attention.

Acknowledgments Dr. Mateen is supported by the American Academy of Neurology Practice Research Fellowship Grant.

Conflicts of interest None.

\section{References}

1. Bleck TP. Historical aspects of critical care and the nervous system. Crit Care Clin. 2009;25:153-64.

2. Sinclair JR, Watters DA, Bagshaw A. Non-traumatic coma in Zambia. Trop Doct. 1989;19:6-10.

3. Brewster DR, Kwiatkowski D, White NJ. Neurological sequelae of cerebral malaria in children. Lancet. 1990;336:1039-43.

4. Carme B, Bougety JC, Plassart H. Mortality and sequelae due to cerebral malaria African children in Brazzaville, Congo. Am J Trop Med Hyg. 1993;48:216-21.

5. Oyelami SA, Olaleye OD, Oyejide CO, Omilabu SA, Fatunla BA. Severe post-vaccination reaction to 17D yellow fever vaccine in Nigeria. Rev Roum Virol. 1994;45:25-30.

6. Shokunbi MT, Solagberu BA. Mortality in childhood head injury in Ibadan. Afr J Med Sci. 1995;24:159-63.

7. Muyembe VM, Suleman N. Head injuries at a Provincial General Hospital in Kenya. East Afr Med J. 1999;76:200-5.

8. Mwangi I, Berkley J, Lowe B, Peshu N, Marsh K, Newton CR. Acute bacterial meningitis in children admitted to a rural Kenyan hospital: increasing antibiotic resistance and outcome. Pediatr Infect Dis J. 2002;21:1042-8.

9. Beye MD, Diouf E, Kane O, Ndoye MD, Seydi A, Ndiave PI, Sall BK. Intensive care management of 28 patients with severe eclampsia in a tropical African setting. Ann Fr Anesth Reanim. 2003;22:25-9.

10. Odebode TO, Abubakhar AM. Childhood head injury: causes, outcome, and outcome predictors. A Nigerian perspective. Pediatr Surg Int. 2004;20:348-52.

11. Aguèmon AR, Padonou JL, Yévègnon SR, Hounkpè PC, Madgougou S, Djagnikpo AK, Atchadé D. Intensive care management 
of patients with severe head traumatism in Benin from 1998-2002. Ann Fr Anesth Reanim. 2005;24:36-9.

12. Bartkovjak M, Ianetti R, Kutna K, Ondrusova A, Kniewzova Z, et al. Cerebral malaria in children in South Sudan: 8 years experience in 261 cases. Neuro Endocrinol Lett. 2007;28(Suppl 2):45-6.

13. Sène Diouf F, Mapoure NY, Ndiave M, Mbatchou Ngahane HB, Touré K, et al. Prognosis of intracerebral hemorrhage with coma in a neurological critical care unit in the tropics. Med Trop (Mars). 2008;68:606-10.

14. Sadarangani M, Seaton C, Scott JA, Ogutu B, Edwards T, Prins A, et al. Incidence and outcome of convulsive status epilepticus in Kenyan children: a cohort study. Lancet Neurol. 2008;7:145-50.

15. Dehayem YM, Kengne AP, Choukem SP, Simo NL, Awah KP, Mbanya JC. The spectrum of coma among people with diabetes in Cameroon: an appraisal of the implications and challenges at the Yaounde Central Hospital. Ann Trop Med Parasitol. 2008;102:73-8
16. Bahloul M, Ben Hamida C, Chelly H, Chaari A, Kallel H, Dammak H, et al. Severe head injury among children: prognostic factors and outcome. Injury. 2009;40:535-40.

17. Wahab KW, Okubadejo NU, Ojini FI, Danesi MA. Predictors of short-term intra-hospital case fatality following first-ever acute ischaemic stroke in Nigerians. J Coll Physicians Surg Pak. 2008;18:755-8.

18. Louriz M, Dendane T, Abidi K, Madani N, Abougal R, Zeggwagh AA. Prognostic factors of acute aluminum phosphide poisoning. Indian J Med Sci. 2009;3:227-34.

19. Chollet F, Tardy J, Albucher JF, et al. Fluoxetine for motor recovery after acute ischaemic stroke (FLAME): a randomized placebo-controlled trial. Lancet Neurol. 2011;10:123-30.

20. Parati G, Kilama MO, Faini A, et al. A new solar-powered blood pressure measuring device for low-resource settings. Hypertension. 2010;56:1047-53. 